Book Review

ISSN: 2162-3104 Print/ ISSN: 2166-3750 Online

Volume 5, Issue 2 (2015), pp. 313-314

(C) Journal of International Students

http://jistudents.org/

\title{
Fostering International Student Success in Higher Education
}

Shapiro, S., Farrelly, R., \& Tomaš, Z. (2014). Fostering international student success in higher education. Alexandria, VA: TESOL, pp. 117; \$34.95 (paperback), ISBN 9781942223207

Reviewed by - Rachel Sherman Johnson, University of Minnesota, Twin Cities (USA)

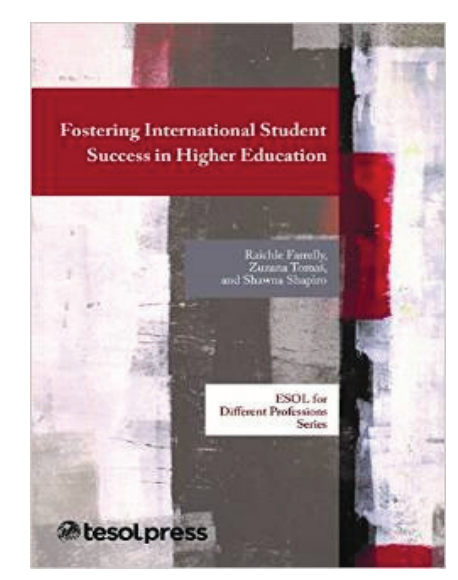

community.

As the number of international students enrolling in Englishdominant higher education continues to rise, this timely book offers university faculty and staff members useful suggestions for responding effectively to the unique needs and challenges of this growing student population. At the same time, though the primary focus is on course design and classroom practice, the book also advocates for international students, noting that they are intellectual, cultural, and linguistic assets to their universities. Shapiro, Farrelly, and Tomaš, all veteran teachers with many years of experience working directly with international students, present a holistic framework for how to support international students' academic development and their integration into the broader campus

The first chapter serves as a foundation for the remainder of the volume by introducing the purpose of the book and providing a short history of recent trends in international education, as well as definitions of key terms. Chapter two is a brief primer on the role that culture plays in the education context, and describes important cultural differences between international and domestic students that may manifest in the classroom. The authors then provide concrete ideas for how to bridge cultures through activities and participation strategies. Throughout this and subsequent chapters, sidebars with quotes from international students add depth, while questions for further reflection encourage additional engagement with the concepts outlined in the primary text.

In chapter three, the authors transition into a discussion of how fundamental principles from second language acquisition (scaffolding, interaction, and noticing) can be applied in nonlanguage instruction. The concepts behind the techniques are described alongside practical advice for how to successfully employ them in lecture, class discussion, and selection of course reading materials. Using these strategies can facilitate students' improved understanding of academic content.

Building on the teaching approaches in chapter three, chapter four provides ideas for assignments and assessments. The authors contend that the purpose of assessment should be to 
allow students to demonstrate what they have learned in a course; as such, they describe equitable assignments as those that help all students, domestic and international alike, display their best work. Thus, the authors focus in this chapter on how to design rubrics, provide explicit instructions, model appropriate work, and give useful feedback.

Chapter five concentrates on the empowerment of international students. While the earlier chapters are mostly comprised of strategies for management of challenges, this chapter reflects the authors' belief that international students also present a wealth of opportunities for their instructors and institutions. The authors offer ideas on how to integrate international students into campus life and engage them as valuable knowledge resources whose perspectives can foster deeper global and intercultural learning for all students. They caution, however, against forcing international students to serve as spokespeople for their respective countries or cultures, and describe ways that instructors can respectfully encourage the sharing of experiences without putting undue pressure on the international students in a class.

The audience for this book is clearly those who are currently engaged in teaching international students, and, as such, the authors do not delve deeply into the theories that underpin research on international student engagement and adjustment. From the standpoint of practice, however, this book is quite useful, as it draws directly from the authors' rich and varied experiences working with international students. The book concludes with a series of appendices that include classroom activities, sample rubrics, and other assessment tips and techniques; these items, in addition to the variety of teaching and course design methods described throughout the text, form a functional and easy to follow roadmap for both experienced instructors and those new to teaching international students. Overall, this book is a highly readable volume that presents solid, classroom-tested ideas for student engagement and learning in a concise and accessible manner. The advice contained in its pages will be informative for many faculty and staff members who hope to better integrate and support the international students on their campuses.

Rachel Sherman Johnson

PhD Candidate, Comparative and International Development Education

University of Minnesota, Twin Cities (USA) 